\title{
OPTIMALISASI PENGGUNAAN ELSE-U UNTUK MATEMATIKA KONSEPTUAL
}

\author{
Luh Putu Ida Harini ${ }^{1 \S}$, Kartika Sari ${ }^{2}$, Eka N. Kencana ${ }^{3}$ \\ ${ }^{1}$ Program Studi Matematika, Fakultas MIPA - Universitas Udayana [Email: ballidah@unud.ac.id] \\ ${ }^{2}$ Program Studi Matematika, Fakultas MIPA - Universitas Udayana [Email:sarikaartika@unud.ac.id] \\ ${ }^{3}$ Grup Riset Sosiometrika, Fakultas MIPA - Universitas Udayana [Email: i.putu.enk@unud.ac.id \\ ${ }^{\S}$ Corresponding Author
}

\begin{abstract}
Udayana University is one of the universities that have developed an e-learning system that is coupled with the IMISSU (Integrated Management Information System of the Udayana) system and is known as the ELSE-U (E-Learning Smart and Elegant of Udayana). This system was built with the aim of accommodating online lectures. But in reality there are still many lecturers, especially in the Mathematics Department who have not utilized the learning media. Many reasons related to the media have not been utilized. In this study, a material development strategy and learning using ELSE$U$ will be initiated for conceptual mathematics material in order to obtain optimal benefits. In addition, the measurement of the level of acceptance and use of the utilization of ELSE-U in learning is carried out using the Technology Acceptance Model (TAM) method. The results showed that the internal and external factors of students did not affect the perceived ease of use in the use of ELSE-U, organizational factors (study programs, faculties, and universities) had a significant effect on perceived usefulness and perceived ease of use in the use of ELSE-U, while student behavior in addressing the use of ELSE-U has a significant effect on students' intention to use it.
\end{abstract}

Keywords: conceptual mathematics, e-learning, SEM, TAM

\section{PENDAhuluan}

Perlu diingat penggunaan e-learning tidak hanya sekedar upload bahan ajar bagi pengajar atau hanya sekedar download dan upload soal dan tugas bagi pembelajar. Sharable Content Object Reference Model (SCORM) merupakan salah satu standard dan spesifikasi e-learning. Pada proses pengembangan materi e-learning, objek pembelajaran digambarkan sesuai dengan fungsinya, hasil belajar dan aktivitas belajar terdefinisi dengan jelas, dan diupayakan untuk membuat deskripsi secara eksplisit sebagai objek reusable untuk skenario pembelajaran yang berbeda. Tingkatan dimana bahan ajar dapat di-reuse dan di-repurpose tergantung pada bagaimana content ini disimpan, disediakan, dan dideliverikan kepada komunitas akademik (Bilfaqih, 2007). Oleh karena itu perlu diadakan study terkait pengembangan, penggunaan dan pengukuran sistem e-learning terhadap objek materi tertentu.

Universitas Udayana adalah salah satu universitas yang telah mengembangkan sistem e-learning yang digandengkan pada sistem IMISSU (Integrated Management Information System the Strategic of Udayana) dan dikenal dengan ELSE-U (E-Learning Smart and Elegant of Udayana). Sistem ini dibangun dengan tujuan untuk mengakomodasikan perkuliahan secara on line. Namun kenyataannya masih banyak dosen khususnya di Jurusan Matematika yang belum memanfaatkan media pembelajaran tersebut. Banyak alasan yang mencul terkait hal itu. Salah satu alasannya adalah keterbatasan pengembangan materi e-learning terutama untuk materi matematika konseptual yang penuh dengan symbol, definisi dan teori. 
Berdasarkan paparan tersebut dalam penelitian ini akan digagas strategi pengembangan materi dan pembelajaran menggunakan ELSE-U untuk materi matematika konseptual agar diperoleh manfaat yang optimal. Selain itu aka dilakukan pengukuran tingkat penerimaan dan penggunaan terhadap pemanfaatan ELSE-U pada pembelajaran dengan menggunakan metode TAM (Technology Acceptance Model).

\section{METODE PENELITIAN}

\section{Populasi \& Sampel Penelitian}

Populasi dan sampel penelitian ini adalah mahasiswa S1 Jurusan Matematika dan S1 Jurusan Ilmu Komputer FMIPA Universitas Udayana yang mengambil mata kuliah Matematika Konseptual (dalam hal ini Analisis Real I dan Matematika Diskret).

\section{Jenis \& Sumber Data}

Data pada penelitian ini diperoleh dengan menyediakan kuesioner untuk diisi secara mandiri (self-administered) oleh mahasiswa yang menjadi sampel. Sebelum kuesioner didistribusikan, validitas item dan reliabilitas kuesioner diperiksa dengan menyebarkannya pada Juli 2017 terhadap 27 orang mahasiswa yang telah menggunakan ELSE-U dalam pembelajarannya. Item yang tidak valid dieliminasi, sehingga yang tersisa adalah
Melalui penelitian ini diharapkan dapat menghasikan bahan/materi e-learning untuk matematika konseptual yang menarik dan terukur dan dapat memberikan masukan kepada USDI selaku pengembang sistem ELSE-U terkait hasil evaluasi tingkat penerimaan dan penggunaan terhadap pemanfaatan sistem ini dalam pembelajaran matematika konseptual.

item-item yang sah digunakan sebagai refleksi dari dimensi pada model konseptual penelitian.

\section{Operasionalisasi Variabel}

Secara konseptual, penelitian evaluasi ELSE-U dengan metode TAM direncanakan memiliki rancangan model seperti terlihat pada gambar berikut:

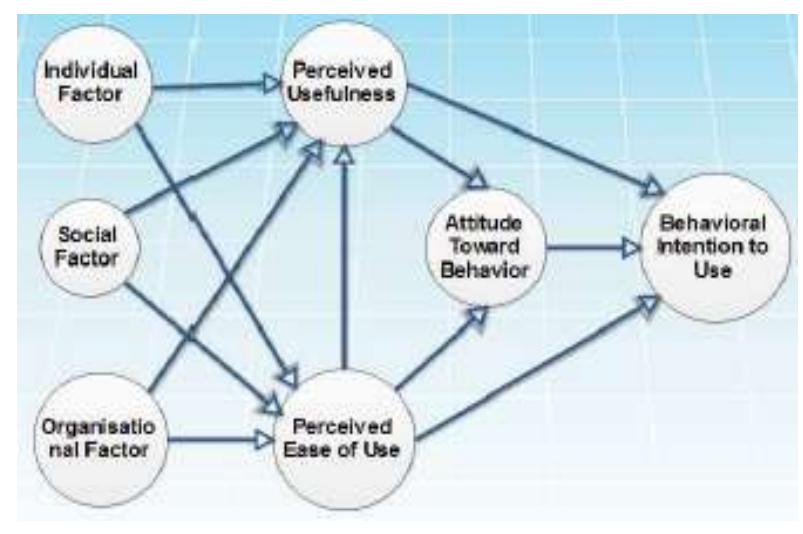

Gambar 1. Model Konseptual Penelitian

Tabel 1. Dimensi dan indikator laten yang diterjemahkan dari Model Konseptual Penelitian

\begin{tabular}{|l|c|l|}
\hline Dimensi & Kode & Deskripsi Pernyataan \\
\hline Individual & $\mathrm{X}_{11}$ & Kecakapan dalam menggunakan komputer \\
\cline { 2 - 3 } & $\mathrm{X}_{12}$ & Keinginan untuk mencoba teknologi pembelajaran yang relatif baru \\
\cline { 2 - 3 } & $\mathrm{X}_{13}$ & Keterjangkauan komputer/laptop \\
\cline { 2 - 3 } & $\mathrm{X}_{14}$ & Kemudahan koneksi internet \\
\hline \multirow{4}{*}{ Social } & $\mathrm{X}_{21}$ & Dukungan finansial dari orangtua \\
\cline { 2 - 3 } & $\mathrm{X}_{22}$ & Pengaruh pergaulan dengan sesama mahasiswa \\
\cline { 2 - 3 } & $\mathrm{X}_{23}$ & Kemudahan berkomunikasi dengan dosen \\
\cline { 2 - 3 } & $\mathrm{X}_{24}$ & Kebutuhan untuk mendukung pekerjaan setelah selesai studi \\
\hline Organisati & $\mathrm{X}_{31}$ & Kemudahan untuk mengakses ELSE-U \\
\cline { 2 - 3 } onal Factor & $\mathrm{X}_{32}$ & Aturan UNUD untuk menerapkan E-Learning pada proses pembelajaran \\
\cline { 2 - 3 } & $\mathrm{X}_{33}$ & Proses pembelajaran yang diterapkan pengajar \\
\cline { 2 - 3 } & $\mathrm{X}_{34}$ & Proses penilaian mata kuliah \\
\hline
\end{tabular}




\begin{tabular}{|l|c|l|}
\hline Dimensi & Kode & \multicolumn{1}{|c|}{ Deskripsi Pernyataan } \\
\hline Perceived & $\mathrm{PU}_{1}$ & E-Learning dapat meningkatkan pemahaman materi kuliah \\
\cline { 2 - 3 } & $\mathrm{PU}_{2}$ & E-Learning dapat meningkatkan produktivitas akademik \\
\cline { 2 - 3 } & $\mathrm{PU}_{3}$ & E-Learning dapat meningkatkan prestasi akademik \\
\cline { 2 - 3 } & $\mathrm{PU}_{4}$ & E-Learning dapat meningkatkan soft-skill di bidang IT \\
\hline \multirow{4}{*}{$\begin{array}{l}\text { Perceived } \\
\text { Use of }\end{array}$} & $\mathrm{PE}_{1}$ & E-Learning mudah dipelajari \\
\cline { 2 - 3 } & $\mathrm{PU}_{2}$ & E-Learning lebih efektif dibandingkan pembelajaran konvensional (tatap muka) \\
\cline { 2 - 3 } & $\mathrm{PU}_{3}$ & E-Learning menyebabkan materi kuliah bisa dipelajari setiap saat \\
\cline { 2 - 3 } $\begin{array}{l}\text { Attitude } \\
\text { Bewards }\end{array}$ & $\mathrm{PU}_{4}$ & E-Learning menyebabkan materi kuliah bisa dipelajari di sembarang tempat \\
\cline { 2 - 3 } & $\mathrm{AB}_{1}$ & Antusias untuk menggunakan E-Learning \\
\cline { 2 - 3 } & $\mathrm{AB}_{2}$ & Penggunaan E-Learning akan sangat membantu pemahaman materi kuliah \\
\cline { 2 - 3 } & $\mathrm{AB}_{3}$ & Penggunaan E-Learning merupakan ide yang sangat positif \\
\cline { 2 - 3 } $\begin{array}{l}\text { Behavioral } \\
\text { Intention } \\
\text { to Use }\end{array}$ & $\mathrm{BI}_{4}$ & Dosen perlu 'dipaksa' menggunakan E-Learning dalam proses pengajaran \\
\cline { 2 - 3 } & $\mathrm{BIU}_{2}$ & Akan memanfaatkan materi kuliah yang menggunakan E-Learning \\
\cline { 2 - 3 } & $\mathrm{BIU}_{3}$ & Akan masuk ke situs ELSE-U secara berkala \\
\cline { 2 - 3 } & $\mathrm{BIU}_{4}$ & Akan menganjurkan dosen lain agar memanfaatkan E-Learning \\
\hline
\end{tabular}

\section{HASIL DAN PEMBAHASAN}

\subsection{Profil Responden}

Responden dari penelitian ini adalah mahasiswa S1 Jurusan Matematika angkatan 2016 (mengambil mata kuliah Matematika Diskret) dan angkatan 2015 (mengambil mata kuliah Analisis Real I) serta mahasiswa S1 Jurusan Ilmu Komputer FMIPA Universitas Udayana angkatan 2017 (mengambil Mata Kuliah Matematika Diskret). Ada hal penting yang menjadi dasar pengambilan responden yaitu terbiasa dan tidak terbiasanya mahasiswa dalam menggunakan komputer.

Karakteristik responden dalam penelitian ini dilihat berdasarkan jenis kelamin, IPK terakhir (kemampuan). Akan tetapi disini ada kelompok yang belum mengetahui IPK nya mengingat mahasiswa Ilmu Komputer yang menjadi responden dalam penelitian ini masih berada pada semester 1. Penelitian ini dilakukan di 3 kelas kuliah dan dengan menyebarkan kuesioner sebanyak 180 buah kepada responden.

\subsection{Kelayakan Instrumen Penelitian}

Langkah awal untuk menguji kebenaran hipotesis adalah menguji validitas dan reliabilitas semua alat ukur yang digunakan dalam penelitian, dalam hal ini adalah kuesioner. Uji validitas dan reliabilitas digunakan untuk mengetahui valid dan reliabelnya instrument atau alat pengumpul data yang digunakan. Uji validitas digunakan untuk menguji valid tidaknya jawaban kuesioner yang telah dijawab oleh responden.

$$
=\frac{r_{x, y}}{\sqrt{\left(n \sum X^{2}-\left(\sum X\right)^{2}\right)}\left(n \sum Y^{2}-\left(\sum Y\right)^{2}\right)}
$$

dengan $r_{X Y}=$ Koefisien validitas, $X=$ Skor yang diperoleh dari setiap item pertanyaan, $Y=$ Skor yang diperoleh dari keseluran item dan $n=$ Jumlah Responden. Selanjutnya nilai dikatakan valid apabila $r_{x, y}>r_{x, y}$ tabel dengan nilai $\mathrm{db}=\mathrm{n}-2$ dan $\alpha$ sebesar 0.05 . Selain itu dilakukan juga uji reliabilitas instrument. Validitas sebuah alat ukur dihitung dengan mencari nilai korelasinya. Korelasi yang diukur adalah korelasi antar skor item terhadap skor total penyusun variabel. Pengujian relaibilitas kuesioner dapat dilihat melalui nilai Cronbach Alpha yang dihasilkan. Jika nilai Cronbach Alpha > 0.6 maka kuesioner dapat dikatakan reliabel. Adapun hubungan konseptual penelitian dan rancangan kuesioner yang terbentuk untuk pemanfaatan ELSE-U adalah sebagai berikut:

A. Untuk Individual Factor dengan:

$\mathrm{X}_{11} \quad$ : Kecakapan dalam menggunakan komputer 
$\mathrm{X}_{12}$ : Keinginan untuk mencoba teknologi pembelajaran yang relatif baru

$\mathrm{X}_{13}$ : Keterjangkauan komputer/laptop

$\mathrm{X}_{14}$ : Kemudahan koneksi internet

diperoleh rancangan pertanyaan berikut:

Saya berkompeten menggunakan

INT1 komputer

$\mathrm{INT}_{2} \quad$ Saya antusias menggunakan teknologi informasi (TI) dalam proses perkuliahan

$\mathrm{INT}_{3} \quad$ Saya memiliki komputer atau laptop untuk mendukung proses perkuliahan

$\mathrm{INT}_{4} \quad$ Saya mudah menjangkau koneksi internet

B. Untuk Social Factor dengan:

$\mathrm{X}_{21}$ : Dukungan finansial dari orangtua

$\mathrm{X}_{22}$ : Pengaruh pergaulan dengan sesama mahasiswa

$\mathrm{X}_{23}$ : Kemudahan berkomunikasi dengan dosen

$\mathrm{X}_{24}$ : Kebutuhan untuk mendukung pekerjaan setelah selesai studi diperoleh rancangan pertanyaan berikut:

$\mathrm{EXT}_{1}$ Saya bersyukur didukung secara penuh oleh orangtua untuk kuliah

$\mathrm{EXT}_{2}$ Saya bergaul dengan kawan-kawan di kampus yang melek TI

$\mathrm{EXT}_{3}$ Dosen di prodi saya menggunakan komputer/LCD proyektor dalam penyampaian materi kuliah Pengetahuan tentang TI sangat $\begin{array}{ll}\mathrm{EXT}_{4} & \text { mem } \\ & \text { kerja }\end{array}$

C. Organisational Factor dengan:

$\mathrm{X}_{31}$ : Kemudahan untuk mengakses ELSE$\mathrm{U}$

$\mathrm{X}_{32}$ : Aturan UNUD untuk menerapkan ELearning pada proses pembelajaran

$\mathrm{X}_{33}$ : Proses pembelajaran yang diterapkan pengajar

$\mathrm{X}_{34}$ : Proses penilaian mata kuliah diperoleh rancangan pertanyaan berikut:

$\mathrm{ORG}_{1} \quad$ Akses yang mudah ke situs ELSEU sangat membantu memahami materi kuliah secara online
$\mathrm{ORG}_{2} \quad$ Aturan UNUD mengenai penggunaan ELSE-U sangat membantu memahami materi kuliah secara online

$\mathrm{ORG}_{3} \quad$ Dosen di prodi saya yang telah menggunakan ELSE-U sangat membantu memahami materi kuliah secara online

$\mathrm{ORG}_{4} \quad$ Proses penilaian matakuliah yang transparan secara online mendorong saya menggunakan ELSE-U

D. Perceived Usefulness dengan:

$\mathrm{PU}_{1}$ : E-Learning dapat meningkatkan pemahaman materi kuliah

$\mathrm{PU}_{2}$ : E-Learning dapat meningkatkan produktivitas akademik

$\mathrm{PU}_{3}$ : E-Learning dapat meningkatkan prestasi akademik

$\mathrm{PU}_{4}$ : E-Learning dapat meningkatkan softskill di bidang IT

diperoleh rancangan pertanyaan berikut:

$\mathrm{PU}_{1}$ Pembelajaran online (E-Learning) meningkatkan pemahaman materi kuliah saya

$\mathrm{PU}_{2} \quad$ Pembelajaran online (E-Learning) menghemat waktu belajar saya

$\mathrm{PU}_{3}$ Pembelajaran online (E-Learning) meningkatkan prestasi akademik saya

$\mathrm{PU}_{4}$ Pembelajaran online (E-Learning) meningkatkan soft skill saya di bidang TI

E. Perceived Ease of Use dengan:

$\mathrm{PE}_{1}$ : E-Learning mudah dipelajari

$\mathrm{PU}_{2}$ : E-Learning lebih efektif dibandingkan pembelajaran konvensional (tatap muka)

$\mathrm{PU}_{3}$ : E-Learning menyebabkan materi kuliah bisa dipelajari setiap saat

$\mathrm{PU}_{4}$ : E-Learning menyebabkan materi kuliah bisa dipelajari di sembarang tempat

diperoleh rancangan pertanyaan berikut:

$\mathrm{PE}_{1} \quad$ Menggunakan cara pembelajaran online (E-Learning) mudah saya pelajari 
$\mathrm{PE}_{2} \quad$ Pembelajaran online (E-Learning) lebih efektif dibandingkan pembelajaran konvensional (tatap muka)

$\mathrm{PE}_{3} \quad$ Pembelajaran online (E-Learning) menyebabkan materi kuliah bisa dipelajari setiap saat

$\mathrm{PE}_{4} \quad$ Pembelajaran online (E-Learning) menyebabkan materi kuliah bisa dipelajari di sembarang tempat

F. Attitude towards Behavior dengan:

$\mathrm{AB}_{1}$ : Antusias untuk menggunakan ELearning

$\mathrm{AB}_{2}$ : Penggunaan E-Learning akan sangat membantu pemahaman materi kuliah

$\mathrm{AB}_{3}$ : Penggunaan E-Learning merupakan ide yang sangat positif

$\mathrm{AB}_{4}$ : Dosen perlu 'dipaksa' menggunakan E-Learning dalam proses pengajaran diperoleh rancangan pertanyaan berikut:

$\mathrm{AB}_{1} \quad$ Saya sangat antusias menggunakan E-Learning

Sangat sangat terbantu dalam

$\mathrm{AB}_{2} \quad$ memahami materi kuliah dengan $E$ Learning

$\mathrm{AB}_{3} \quad$ Penggunaan E-Learning merupakan terobosan yang sangat positif Saya menganggap seharusnya

$\mathrm{AB}_{4} \quad$ seluruh dosen menggunakan $E$ learning

G. Behavioral Intention to Use dengan:

$\mathrm{AB}_{1}$ : Akan memanfaatkan materi kuliah yang menggunakan E-Learning
$\mathrm{AB}_{2}$ : Akan masuk ke situs ELSE-U secara berkala

$\mathrm{AB}_{3}$ : Akan merekomendasikan kawan untuk menggunakan E-Learning

$\mathrm{AB}_{4}$ : Akan menganjurkan dosen lain agar memanfaatkan E-Learning

diperoleh rancangan pertanyaan berikut:

$\mathrm{AB}_{1} \quad$ Saya sangat antusias menggunakan E-Learning

Sangat sangat terbantu dalam

$\mathrm{AB}_{2} \quad$ memahami materi kuliah dengan $E$ -

Learning

$\mathrm{AB}_{3} \quad$ Penggunaan E-Learning merupakan terobosan yang sangat positif Saya menganggap seharusnya

$\mathrm{AB}_{4} \quad$ seluruh dosen menggunakan $E$ learning

Untuk uji validitas kuesioner ini akan diujikan kepada 20 orang mahasiswa yang telah berpengalaman menggunakan e-learning diluar mahasiswa yang akan dijadikan sampel.

Sebelum dapat digunakan sebagai instrumen pengumpul data, kuesioner yang dirancang pada penelitian ini harus diperiksa kelayakannya, meliputi validitas setiap item yang merefleksikan konsep atau laten yang diteliti, dan reliabilitas dari konsep atau laten tersebut. Melalui penyebaran kepada 20 mahasiswa Program Studi (Prodi) Matematika Universitas Udayana, kelayakan dari kuesioner penelitian ini diperiksa. Pengujian dilakukan menggunakan program SPSS versi 20 dengan hasil analisis ditunjukan pada Tabel 2. 
Tabel2. Uji Kelayakan Kuesioner Penelitian Optimalisasi Pemanfaatan ELSE-U Sebagai Media Pembelajaran Matematika Konseptual

\begin{tabular}{|c|c|c|c|c|}
\hline $\begin{array}{l}\text { Konsep atau } \\
\text { Variabel Laten }\end{array}$ & \multicolumn{2}{|c|}{ Kode Item dan Pernyataan Diringkas } & \multirow{2}{*}{$\begin{array}{r}\text { Korelasi } \\
\text { Item - Total } \\
0.469\end{array}$} & \multirow{2}{*}{$\begin{array}{r}\text { Nilai } \boldsymbol{\alpha} \\
\text { Bila Dihapus } \\
0.456\end{array}$} \\
\hline \multirow{4}{*}{$\begin{array}{l}\text { Faktor Individu } \\
(\alpha=0.596)\end{array}$} & $\mathrm{INT}_{1}$ & $\begin{array}{l}\text { Mahasiswa kompeten dalam menggunakan } \\
\text { komputer }\end{array}$ & & \\
\hline & $\mathrm{INT}_{2}$ & $\begin{array}{l}\text { Mahasiswa antusias menggunakan TI } \\
\text { dalam proses perkuliahan }\end{array}$ & 0.358 & 0.539 \\
\hline & $\mathrm{INT}_{3}$ & Mahasiswa memiliki laptop/komputer & 0.417 & 0.496 \\
\hline & $\mathrm{INT}_{4}$ & Internet terjangkau & 0.286 & 0.608 \\
\hline \multirow{4}{*}{$\begin{array}{l}\text { Faktor Sosial } \\
(\alpha=0.705)\end{array}$} & $\mathrm{EXT}_{1}$ & $\begin{array}{l}\text { Adanya dukungan penuh keluarga untuk } \\
\text { kuliah }\end{array}$ & 0.486 & 0.645 \\
\hline & $\mathrm{EXT}_{2}$ & $\begin{array}{l}\text { Pergaulan dengan sesama mahasiswa yang } \\
\text { melek TI }\end{array}$ & 0.236 & 0.775 \\
\hline & $\mathrm{EXT}_{3}$ & $\begin{array}{l}\text { Dosen menggunakan LCD/Proyektor } \\
\text { dalam menyampaikan materi }\end{array}$ & 0.520 & 0.623 \\
\hline & $\mathrm{EXT}_{4}$ & $\begin{array}{l}\text { Pengetahuan tentang TI merupakan nilai } \\
\text { tambah ke dunia kerja }\end{array}$ & 0.763 & 0.458 \\
\hline \multirow{4}{*}{$\begin{array}{l}\text { Faktor Organisasi } \\
(\alpha=0.939)\end{array}$} & $\mathrm{ORG}_{1}$ & Situs ELSE-U mudah diakses & 0.877 & 0.913 \\
\hline & $\mathrm{ORG}_{2}$ & $\begin{array}{l}\text { Pedoman menggunakan ELSE-U sangat } \\
\text { membantu }\end{array}$ & 0.746 & 0.953 \\
\hline & $\mathrm{ORG}_{3}$ & $\begin{array}{l}\text { Penggunaan ELSE-U oleh dosen } \\
\text { membantu pemahaman materi kuliah }\end{array}$ & 0.944 & 0.889 \\
\hline & $\mathrm{ORG}_{4}$ & $\begin{array}{l}\text { Penilaian yang transparan mendorong } \\
\text { menggunakan ELSE-U }\end{array}$ & 0.855 & 0.919 \\
\hline \multirow{4}{*}{$\begin{array}{l}\text { Perceived } \\
\text { Usefulness } \\
(\alpha=0.898)\end{array}$} & $\mathrm{PU}_{1}$ & $\begin{array}{l}\text { E-Learning meningkatkan pemahaman } \\
\text { materi kuliah }\end{array}$ & 0.796 & 0.865 \\
\hline & $\mathrm{PU}_{2}$ & E-Learning menghemat waktu belajar & 0.679 & 0.902 \\
\hline & $\mathrm{PU}_{3}$ & $\begin{array}{l}\text { E-Learning meningkatkan prestasi } \\
\text { akademik }\end{array}$ & 0.844 & 0.842 \\
\hline & $\mathrm{PU}_{4}$ & $\begin{array}{l}\text { E-Learning meningkatkan soft skill di } \\
\text { bidang TI }\end{array}$ & 0.810 & 0.858 \\
\hline \multirow{4}{*}{$\begin{array}{l}\text { Perceived Ease } \\
\text { to Use } \\
(\alpha=0.749)\end{array}$} & $\mathrm{PEU}_{1}$ & Pembelajaran daring mudah dipelajari & 0.474 & 0.743 \\
\hline & $\mathrm{PEU}_{2}$ & $\begin{array}{l}\text { Pembelajaran daring lebih efektif } \\
\text { dibandingkan tatap muka }\end{array}$ & 0.505 & 0.718 \\
\hline & $\mathrm{PEU}_{3}$ & $\begin{array}{l}\text { Pembelajaran daring menyebabkan materi } \\
\text { kuliah setiap saat bisa dipelajari }\end{array}$ & 0.690 & 0.624 \\
\hline & $\mathrm{PEU}_{4}$ & $\begin{array}{l}\text { Pembelajaran daring menyebabkan materi } \\
\text { kuliah bisa dipelajari di mana saja }\end{array}$ & 0.567 & 0.686 \\
\hline \multirow{4}{*}{$\begin{array}{l}\text { Attitude toward } \\
\text { Behavior } \\
(\alpha=0.509)\end{array}$} & $\mathrm{AB}_{1}$ & $\begin{array}{l}\text { Mahasiswa antusias menggunakan } \\
\text { pembelajaran daring }\end{array}$ & 0.465 & 0.279 \\
\hline & $\mathrm{AB}_{2}$ & $\begin{array}{l}\text { Mahasiswa terbantu untuk memahami } \\
\text { materi melalui pembelajaran daring }\end{array}$ & 0.087 & 0.575 \\
\hline & $\mathrm{AB}_{3}$ & $\begin{array}{l}\text { Pembelajaran daring merupakan terobosan } \\
\text { UNUD yang positif }\end{array}$ & 0.436 & 0.295 \\
\hline & $\mathrm{AB}_{4}$ & $\begin{array}{l}\text { Seharusnya sebagian besar dosen } \\
\text { menggunakan ELSE-U }\end{array}$ & 0.234 & 0.510 \\
\hline \multirow{4}{*}{$\begin{array}{l}\text { Behavioral } \\
\text { Intention to Use } \\
(\alpha=0.866)\end{array}$} & $\mathrm{BIU}_{1}$ & $\begin{array}{l}\text { Mahasiswa menggunakan ELSE-U secara } \\
\text { rutin }\end{array}$ & 0.744 & 0.823 \\
\hline & $\mathrm{BIU}_{2}$ & Mahasiswa login secara rutin ke ELSE-U & 0.582 & 0.881 \\
\hline & $\mathrm{BIU}_{3}$ & $\begin{array}{l}\text { Akan menganjurkan kawan menggunakan } \\
\text { ELSE-U }\end{array}$ & 0.820 & 0.784 \\
\hline & $\mathrm{BIU}_{4}$ & $\begin{array}{l}\text { Akan mengusulkan dosen agar } \\
\text { menggunakan ELSE-U }\end{array}$ & 0.740 & 0.819 \\
\hline
\end{tabular}

Sumber: Data Primer (2017), Dianalisis 
Pada penelitian ini, uji validitas dan reliabilitas kuesioner dilakukan secara terpisah untuk setiap dimensi yang disertakan. Pada dimensi faktor internal, tiga item pertama memiliki koefisien korelasi $(\rho)$ item dengan nilai totalnya melebihi nilai batas bawah yang dipersyaratkan sebesar 0.30 (Nunnaly, 1975), dan item $\mathrm{INT}_{4}$ memiliki $\rho$ item sedikit lebih kecil. Meskipun demikian, mempertimbangkan (a) keterjangkauan koneksi internet diduga memengaruhi prilaku individu mahasiswa dalam menggunakan ELSE-U dan (b) bila item ini dieliminasi hanya mengakibatkan penambahan kecil dari nilai $\alpha$ Cronbach menjadi 0.608 dari nilai sebelumnya 0.596 ; maka item ini dipertahankan, tetapi pernyataannya dimodifikasi agar lebih mudah dipahami oleh responden. Pernyataan pada item $\mathrm{INT}_{4}$ diubah menjadi Koneksi internet di tempat tinggal saya (rumah atau tempat kost) stabil dengan harga terjangkau.

Pada dimensi faktor sosial, tiga dari empat pernyataan memiliki koefisien korelasi melebihi nilai 0.30, kecuali item $\mathrm{EXT}_{2}$ (lingkungan pergaulan yang melek $\mathrm{TI}$ ) yang memiliki nilai koefisien korelasi hanya sebesar 0.236. Mempertimbangkan bila item ini dikeluarkan menyebabkan nilai koefisien a Cronbach meningkat menjadi 0.775 dari nilai sebelumnya 0.705, maka diputuskan untuk mengeliminasi $\mathrm{EXT}_{2}$ dari daftar pernyataan pada kuesioner.

Pada Tabel 2. terlihat bahwa untuk setiap pernyataan yang digunakan untuk mengukur dimensi Faktor Organisasi, Perceived Usefulness, Perceived Ease to Use, dan Behavioral Intention to Use memiliki nilai corrected item-total correlation masing-masing selalu lebih besar dari 0,3. Hal tersebut menunjukkan bahwa untuk setiap pernyataan yang digunakan untuk mengukur dimensi Faktor Organisasi, Perceived Usefulness, Perceived Ease to Use, dan Behavioral Intention to Use yang telah diujikan pada 20 responden bernilai valid karena sebuah item pernyataan dinyatakan valid dalam suatu pengukuran apabila memiliki nilai korelasi lebih dari 0,3. Sedangkan nilai Cronbach Alpha dari setiap dimensi dimensi Faktor Organisasi, Perceived Usefulness, Perceived Ease to Use, dan Behavioral Intention to Use memiliki nilai cronbach alpha lebih dari 0,7 . Hal ini nyatakan bahwa suatu instrument pengukuran yang digunakan untuk mengukur dimensi Faktor Organisasi, Perceived Usefulness, Perceived Ease to Use, dan Behavioral Intention to Use dapat dipercaya karena untuk setiap dimensi memiliki nilai Cronbach Alpha lebih dari 0.70 .

Pada dimensi attitude toward behavior, dua dari empat pernyataan memiliki koefisien korelasi melebihi nilai 0.30, yaitu $\mathrm{AB}_{1}$ dan $\mathrm{AB}_{3}$. Sedangkan item $\mathrm{AB}_{2}$ dan $\mathrm{AB}_{4}$ hanya memiliki nilai koefisien korelasi sebesar 0.087 dan 0,234. Mempertimbangkan bila item ini dikeluarkan menyebabkan nilai koefisien $\alpha$ Cronbach hampir menyamai nilai sebelumnya maka diputuskan untuk mengeliminasi $\mathrm{AB}_{2}$ dan $\mathrm{AB}_{4}$ dari daftar pernyataan pada kuesioner.

\section{Evaluasi Model Pengukuran}

Measurement model merupakan sub-model pada model persamaan struktural yang digunakan untuk menggambarkan hubungan variabel laten dengan indikator-indikator pengukurnya memerhatikan variabel laten tidak dapat diukur secara langsung (Hair et al., 2013). Pengukuran pada indikator reflektif xi indikator yang direfleksikan oleh variabel laten $\xi j$ - bisa dinyatakan melalui persamaan (1)

$x_{i}=\gamma_{0 \mathrm{j}}+\gamma_{1 \mathrm{j}} \xi_{\mathrm{j}}+\delta_{i} ; i=1, \ldots, p ; j=1, \ldots, q$

Pada persamaan (1), $p$ menyatakan jumlah indikator reflektif pada laten ke-j dan $q=$ jumlah variabel laten dengan indikator reflektif dalam model persamaan struktural. Pada tahapan analisis, $x_{i}$ dan $\xi_{\mathrm{j}}$ dinyatakan dalam bentuk yang dibakukan sehingga suku $\gamma_{0 j}$ tereliminasi dari persamaan (1). Sebuah model persamaan struktural, sebelum hipotesis yang dibangun peneliti dapat diuji, setiap blok hubungan kausal antara sebuah variabel laten dengan indikator-indikator reflektifnya harus divalidasi terlebih dahulu dengan memeriksa 
composite reliability (CR), convergent validity (CV), dan discriminant validity (DV).

Tabel 3 menampilkan nilai-nilai $\mathrm{CR}$ yang menggambarkan konsistensi internal variabel laten dengan indikator-indikator reflektifnya, dan average variance extracted (AVE) yang

Tabel 3. Sub-Model Pengukuran dari Optimalisasi Pemanfaatan ELSE-U Sebagai Media Pembelajaran Matematika Konseptual

\begin{tabular}{|c|c|c|c|c|c|c|}
\hline \multirow{2}{*}{ Variabel Laten } & \multirow{2}{*}{ CR } & \multirow{2}{*}{ AVE } & \multicolumn{2}{|r|}{ Indikator Reflektif } & \multirow{2}{*}{$\begin{array}{r}\text { Factor } \\
\text { Loading } \\
\end{array}$} & \multirow{2}{*}{$\begin{array}{r}\mathrm{p}- \\
\text { Value } \\
\end{array}$} \\
\hline & & & Kode & Pernyataan Diringkas & & \\
\hline \multirow{4}{*}{ Faktor Internal } & \multirow{4}{*}{$\frac{0.686}{0.744}$} & \multirow{4}{*}{$\frac{0.387}{0.501}$} & $\mathrm{INT}_{1}$ & Kompeten menggunakan komputer & $\begin{array}{l}0.691 \\
0.685\end{array}$ & 0.000 \\
\hline & & & $\mathrm{INT}_{2}$ & $\begin{array}{l}\text { Antusias menggunakan TI dalam proses } \\
\text { perkuliahan }\end{array}$ & 0.840 & 0.000 \\
\hline & & & $\mathrm{INT}_{3}$ & Memiliki komputer atau laptop & 0.218 & 0.311 \\
\hline & & & $\mathrm{INT}_{4}$ & Mudah menjangkau koneksi internet & $\begin{array}{l}0.563 \\
0.545\end{array}$ & 0.000 \\
\hline \multirow{3}{*}{ Faktor Eksternal } & \multirow{3}{*}{0.771} & \multirow{3}{*}{0.539} & $\mathrm{EXT}_{1}$ & Dukungan orangtua untuk kuliah & 0.552 & 0.001 \\
\hline & & & $\mathrm{EXT}_{3}$ & Penggunaan LCD/Proyektor oleh dosen & 0.697 & 0.000 \\
\hline & & & $\mathrm{EXT}_{4}$ & $\begin{array}{l}\text { Pengetahuan tentang TI merupakan nilai } \\
\text { tambah ke dunia kerja }\end{array}$ & 0.909 & 0.000 \\
\hline \multirow{4}{*}{$\begin{array}{l}\text { Faktor } \\
\text { Organisasi }\end{array}$} & \multirow{4}{*}{0.917} & \multirow{4}{*}{0.735} & $\mathrm{ORG}_{1}$ & Situs ELSE-U mudah diakses & 0.827 & 0.000 \\
\hline & & & $\mathrm{ORG}_{2}$ & Pedoman ELSE-U sangat membantu & 0.902 & 0.000 \\
\hline & & & $\mathrm{ORG}_{3}$ & $\begin{array}{l}\text { ELSE-U oleh dosen membantu } \\
\text { pemahaman materi kuliah }\end{array}$ & 0.860 & 0.000 \\
\hline & & & $\mathrm{ORG}_{4}$ & Penilaian yang transparan & 0.838 & 0.000 \\
\hline \multirow{4}{*}{$\begin{array}{l}\text { Perceived } \\
\text { Usefulness }\end{array}$} & \multirow{4}{*}{0.888} & \multirow{4}{*}{0.671} & $\mathrm{PU}_{1}$ & $\begin{array}{l}\text { E-Learning meningkatkan pemahaman } \\
\text { materi kuliah }\end{array}$ & 0.911 & 0.000 \\
\hline & & & $\mathrm{PU}_{2}$ & E-Learning menghemat waktu belajar & 0.871 & 0.000 \\
\hline & & & $\mathrm{PU}_{3}$ & E-Learning meningkatkan prestasi akademik & 0.870 & 0.000 \\
\hline & & & $\mathrm{PU}_{4}$ & $\begin{array}{l}\text { E-Learning meningkatkan soft skill di } \\
\text { bidang TI }\end{array}$ & 0.583 & 0.000 \\
\hline \multirow{4}{*}{$\begin{array}{l}\text { Perceived Ease } \\
\text { to Use }\end{array}$} & \multirow{4}{*}{0.793} & \multirow{4}{*}{$\underline{0.494}$} & $\mathrm{PEU}_{1}$ & Pembelajaran daring mudah dipelajari & 0.672 & 0.000 \\
\hline & & & $\mathrm{PEU}_{2}$ & $\begin{array}{l}\text { Pembelajaran daring lebih efektif } \\
\text { dibandingkan tatap muka }\end{array}$ & 0.570 & 0.000 \\
\hline & & & $\mathrm{PEU}_{3}$ & $\begin{array}{l}\text { Pembelajaran daring menyebabkan materi } \\
\text { kuliah setiap saat bisa dipelajari }\end{array}$ & 0.808 & 0.000 \\
\hline & & & $\mathrm{PEU}_{4}$ & $\begin{array}{l}\text { Pembelajaran daring menyebabkan materi } \\
\text { kuliah bisa dipelajari di mana saja }\end{array}$ & 0.739 & 0.000 \\
\hline \multirow{2}{*}{$\begin{array}{l}\text { Attitude toward } \\
\text { Behavior }\end{array}$} & \multirow[b]{2}{*}{0.893} & \multirow[b]{2}{*}{0.807} & $\mathrm{AB}_{1}$ & Antusias menggunakan pembelajaran daring & 0.921 & 0.000 \\
\hline & & & $\mathrm{AB}_{3}$ & $\begin{array}{l}\text { Pembelajaran daring merupakan terobosan } \\
\text { UNUD yang positif }\end{array}$ & 0.875 & 0.000 \\
\hline \multirow{4}{*}{$\begin{array}{l}\text { Behavioral } \\
\text { Intention to Use }\end{array}$} & \multirow{4}{*}{0.911} & \multirow{4}{*}{0.720} & $\mathrm{BIU}_{1}$ & Menggunakan ELSE-U secara rutin & 0.769 & 0.000 \\
\hline & & & $\mathrm{BIU}_{2}$ & Login ke ELSE-U secara rutin & 0.861 & 0.000 \\
\hline & & & $\mathrm{BIU}_{3}$ & $\begin{array}{l}\text { Akan menganjurkan kawan menggunakan } \\
\text { ELSE-U }\end{array}$ & 0.892 & 0.000 \\
\hline & & & $\mathrm{BIU}_{4}$ & $\begin{array}{l}\text { Akan mengusulkan dosen agar } \\
\text { menggunakan ELSE-U }\end{array}$ & 0.867 & 0.000 \\
\hline
\end{tabular}

Keterangan : $\quad$ Item $\mathrm{INT}_{3}$ Dieliminasi

Nilai Setelah $\mathrm{INT}_{3}$ Dieliminasi

Sumber: Data Primer (2017)

Tabel 3 memperlihatkan terdapat 2 variabel laten, faktor internal individu dan perceived ease to use memiliki nilai CR atau AVE yang lebih rendah dari ambang bawah yang menunjukkan CV dari variabel laten. Mengacu Hair et al. (2013), agar terbentuk konsistensi internal maka $\mathrm{CR} \geq 0.708$; dan agar terjadi validitas konvergensi dari variabel laten maka nilai AVE $\geq 0.50$ (Peng \& Lai, 2012). 
dengan signifikansi 0.311 jauh lebih besar dari nilai $\alpha=0.10$ sebagai nilai signifikansi terbesar yang lazim digunakan pada riset di bidang ilmu sosial humaniora. Hal yang sama dilakukan pada 4 indikator dari laten perceived ease to use. Seluruh indikator pada laten ini signifikan pada taraf uji $\alpha=0.10$. Mencermati hal ini dan nilai AVE dari laten sebesar 0.494 sedikit lebih kecil dari nilai ambang 0.50; maka diputuskan untuk mempertahankan keempat indikator dari variabel laten ini.

Berbeda dengan indikator pada laten perceived ease to use yang dipertahankan seluruhnya, indikator $\mathrm{INT}_{3}$ dikeluarkan sebagai refleksi laten faktor internal dan analisis diulangi. Hasil analisis pada model pengukuran setelah dikeluarkannya $\mathrm{INT}_{3}$ memperlihatkan laten ini telah memiliki nilai CR dan AVE melebihi nilai ambang bawah yang dipersyaratkan. Dengan demikian, evaluasi model struktural dan hipotesis yang dikembangkan bisa dilakukan.

\section{Evaluasi Model Struktural dan Uji Hipotesis}

Penelitian ini mengembangkan 11 hipotesis mengenai signifikansi dari hubungan kausal yang terbentuk antarlaten (lihat gambar 2).

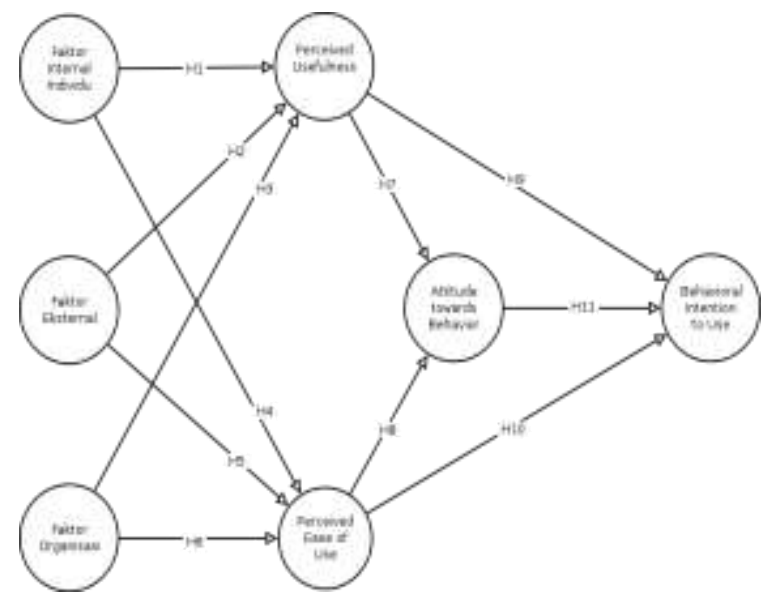

Gambar 2. Hipotesis pada Hubungan kausal antarvariabel Laten

Dari gambar 2. diperoleh hipotesis-hipotesis sebagai berikut:
$\mathrm{H}_{1}$ : Faktor internal mahasiswa berpengaruh terhadap perceived usefulness pada penggunaan ELSE-U;

$\mathrm{H}_{2}$ : Faktor eksternal mahasiswa berpengaruh terhadap perceived usefulness pada penggunaan ELSE-U;

$\mathrm{H}_{3}$ : Faktor organisasi (program studi, fakultas, dan universitas) berpengaruh terhadap perceived usefulness pada penggunaan ELSE-U;

$\mathrm{H}_{4}$ : Faktor internal mahasiswa berpengaruh terhadap perceived ease of use pada penggunaan ELSE-U;

$\mathrm{H}_{5}$ : Faktor eksternal mahasiswa berpengaruh terhadap perceived ease of use pada penggunaan ELSE-U;

$\mathrm{H}_{6}$ : Faktor organisasi (program studi, fakultas, dan universitas) berpengaruh terhadap perceived ease of use pada penggunaan ELSE-U;

$\mathrm{H}_{7}$ : perceived usefulness berpengaruh pada prilaku mahasiswa dalam menyikapi penggunaan ELSE-U;

$\mathrm{H}_{8} \quad$ : perceived ease of use berpengaruh pada prilaku mahasiswa dalam menyikapi penggunaan ELSE-U;

$\mathrm{H}_{9}$ : perceived usefulness berpengaruh pada niat mahasiswa untuk menggunakan ELSE-U;

$\mathrm{H}_{10}$ : prilaku mahasiswa dalam menyikapi penggunaan ELSE-U berpengaruh pada niat mahasiswa untuk menggunakannya; dan

$\mathrm{H}_{11}$ : perceived ease of use berpengaruh pada niat mahasiswa untuk menggunakan ELSE-U.

Pada evaluasi model struktural, SmartPLS yang digunakan menganalisis data diatur untuk melakukan proses bootstrap sebanyak 1000 sampel. Koefisien-koefisien jalur yang menghubungkan laten eksogenus dengan laten endogenus diperlihatkan pada tabel 4 : 
Tabel 4. Koefisien Jalur antarvariabel Laten dan Signifikansinya

\begin{tabular}{|c|c|c|c|c|c|}
\hline $\begin{array}{l}\text { Hipotesis } \\
\text { Penelitian }\end{array}$ & Laten Eksogen & Laten Endogen & $\begin{array}{r}\text { Nilai } \\
\text { Koefisien } \\
\text { Jalur }\end{array}$ & $\mathrm{p}$-Value & Keterangan \\
\hline $\mathrm{H}_{1}$ & Faktor Internal Individu & Perceived Usefulness & 0.226 & 0.001 & Sangat Signifikan \\
\hline $\mathrm{H}_{2}$ & Faktor Eksternal & Perceived Usefulness & 0.098 & 0.095 & Quasi Signifikan \\
\hline $\mathrm{H}_{3}$ & Faktor Organisasi & Perceived Usefulness & 0.573 & 0.000 & Sangat Signifikan \\
\hline $\mathrm{H}_{4}$ & Faktor Internal Individu & Perceived Ease of Use & 0.078 & 0.451 & Tidak Signifikan \\
\hline $\mathrm{H}_{5}$ & Faktor Eksternal & Perceived Ease of Use & 0.103 & 0.284 & Tidak Signifikan \\
\hline $\mathrm{H}_{6}$ & Faktor Organisasi & Perceived Ease of Use & 0.480 & 0.000 & Sangat Signifikan \\
\hline $\mathrm{H}_{7}$ & Perceived Usefulness & Attitude toward Behavior & 0.195 & 0.075 & Quasi Signifikan \\
\hline $\mathrm{H}_{8}$ & Perceived Ease of Use & Attitude toward Behavior & 0.632 & 0.000 & Sangat Signifikan \\
\hline $\mathrm{H}_{9}$ & Perceived Usefulness & Behavioral Intention to Use & 0.194 & 0.097 & Quasi Signifikan \\
\hline $\mathrm{H}_{10}$ & Attitude toward Behavior & Behavioral Intention to Use & 0.375 & 0.003 & Sangat Signifikan \\
\hline $\mathrm{H}_{11}$ & Perceived Ease of Use & Behavioral Intention to Use & 0.198 & 0.094 & Quasi Signifikan \\
\hline erangan & $\begin{array}{l}\text { Tidak Signifikan } \\
\text { Quasi Signifikan } \\
\text { Signifikan : } 0.01<\alpha \leq \\
\text { Tidak Signifikan }\end{array}$ & $\begin{array}{l}0.10 \\
5<\alpha \leq 0.10 \\
5 \\
0.01\end{array}$ & & & \\
\hline
\end{tabular}

Sumber: Data Primer (2017), Dianalisis

\section{Uji Hipotesis dan Interpretasi}

Hipotesis-hipotesis yang dibentuk pada penelitian ini dapat diuji dengan menggunakan $p$-value dan koefisien jalur yang telah diperoleh pada Tabel 5.3. sebagai berikut:

1. Faktor internal mahasiswa berpengaruh terhadap perceived usefulness pada penggunaan ELSE-U. Adapun hipotesis yang diuji dalam hal ini sebagai berikut:

$H_{0}$ : Faktor internal mahasiswa tidak mempengaruhi perceived usefulness pada penggunaan ELSE-U

$H_{1}:$ Faktor internal mahasiswa mempengaruhi perceived usefulness pada penggunaan ELSE-U

Hubungan antara variabel faktor internal mahasiswa dengan perceived usefulness pada penggunaan ELSE-U memiliki nilai koefisien jalur sebesar 0.226. dan diperoleh $p$-value sebesar 0.001 yang lebih kecil dari 0.05 sehingga keputusan yang diambil adalah menolak $\mathrm{H}_{0}$. Hal ini berarti sarana Faktor internal mahasiswa berpengaruh signifikan terhadap perceived usefulness pada penggunaan ELSE-U.

2. Faktor eksternal mahasiswa berpengaruh terhadap perceived usefulness pada penggunaan ELSE-U. Adapun hipotesis yang diuji dalam hal ini sebagai berikut:

$H_{0}$ : Faktor eksternal mahasiswa tidak mempengaruhi perceived usefulness pada penggunaan ELSE-U

$H_{1}$ : Faktor eksternal mahasiswa mempengaruhi perceived usefulness pada penggunaan ELSE-U

Hubungan antara variabel faktor internal mahasiswa dengan perceived usefulness pada penggunaan ELSE-U memiliki nilai koefisien jalur sebesar 0.098. dan diperoleh $p$-value sebesar 0.095 yang lebih kecil dari 0.05 sehingga keputusan yang diambil adalah menolak $\mathrm{H}_{0}$. Hal ini berarti sarana Faktor eksternal mahasiswa berpengaruh quasi signifikan terhadap perceived usefulness pada penggunaan ELSE-U.

3. Faktor organisasi (program studi, fakultas, dan universitas) berpengaruh terhadap perceived usefulness pada penggunaan ELSE-U. Adapun hipotesis yang diuji dalam hal ini sebagai berikut:

$H_{0}$ : Faktor organisasi (program studi, fakultas, dan universitas) tidak mempengaruhi perceived usefulness pada penggunaan ELSE-U

$H_{1}$ : Faktor organisasi (program studi, fakultas, dan universitas) tidak 
mempengaruhi perceived usefulness pada penggunaan ELSE-U

Hubungan antara variabel Faktor organisasi (program studi, fakultas, dan universitas) dengan perceived usefulness pada penggunaan ELSE-U memiliki nilai koefisien jalur sebesar 0.573. dan diperoleh $p$-value sebesar 0.000 yang lebih kecil dari 0.05 sehingga keputusan yang diambil adalah menolak $\mathrm{H}_{0}$. Hal ini berarti sarana Faktor organisasi (program studi, fakultas, dan universitas) berpengaruh signifikan terhadap perceived usefulness pada penggunaan ELSE-U.

4. Faktor internal mahasiswa berpengaruh terhadap perceived ease of use pada penggunaan ELSE-U. Adapun hipotesis yang diuji dalam hal ini sebagai berikut:

$H_{0}$ : Faktor internal mahasiswa tidak mempengaruhi perceived ease of use pada penggunaan ELSE-U

$H_{1}$ : Faktor internal mahasiswa tidak mempengaruhi perceived ease of use pada penggunaan ELSE-U

Hubungan antara variabel faktor internal mahasiswa dengan perceived ease of use pada penggunaan ELSE-U memiliki nilai koefisien jalur sebesar 0.078. dan diperoleh $p$-value sebesar 0.451 yang lebih besar dari 0.05 sehingga keputusan yang diambil adalah menerima $\mathrm{H}_{0}$. Hal ini berarti sarana Faktor internal mahasiswa tidak mempengaruhi perceived ease of use pada penggunaan ELSE$\mathrm{U}$

5. Faktor eksternal mahasiswa berpengaruh terhadap perceived ease of use pada penggunaan ELSE-U. Adapun hipotesis yang diuji dalam hal ini sebagai berikut:

$H_{0}$ : Faktor eksternal mahasiswa tidak mempengaruhi perceived ease of use pada penggunaan ELSE-U

$H_{1}$ : Faktor eksternal mahasiswa mempengaruhi perceived ease of use pada penggunaan ELSE-U

Hubungan antara variabel faktor eksternal mahasiswa dengan perceived ease of use pada penggunaan ELSE-U memiliki nilai koefisien jalur sebesar 0.103. dan diperoleh $p$-value sebesar 0.284 yang lebih besar dari 0.05 sehingga keputusan yang diambil adalah menerima $\mathrm{H}_{0}$. Hal ini berarti sarana faktor eksternal mahasiswa tidak berpengaruh terhadap perceived usefulness pada penggunaan ELSE-U

6. Faktor organisasi (program studi, fakultas, dan universitas) berpengaruh terhadap perceived ease of use pada penggunaan ELSE-U. Adapun hipotesis yang diuji dalam hal ini sebagai berikut:

$H_{0}$ : Faktor organisasi (program studi, fakultas, dan universitas) tidak berpengaruh terhadap perceived ease of use pada penggunaan ELSE-U

$H_{1}$ : Faktor organisasi (program studi, fakultas, dan universitas) berpengaruh terhadap perceived ease of use pada penggunaan ELSE-U

Hubungan antara variabel Faktor organisasi (program studi, fakultas, dan universitas) berpengaruh terhadap perceived ease of use pada penggunaan ELSE-U memiliki nilai koefisien jalur sebesar 0.480. dan diperoleh $p$-value sebesar 0.000 yang lebih kecil dari 0.05 sehingga keputusan yang diambil adalah menolak $\mathrm{H}_{0}$. Hal ini berarti sarana Faktor organisasi (program studi, fakultas, dan universitas) berpengaruh signifikan terhadap perceived ease of use pada penggunaan ELSE$\mathrm{U}$.

7. perceived usefulness berpengaruh pada prilaku mahasiswa dalam menyikapi penggunaan ELSE-U. Adapun hipotesis yang diuji dalam hal ini sebagai berikut:

$H_{0}$ : perceived usefulness tidak berpengaruh pada prilaku mahasiswa dalam menyikapi penggunaan ELSE-U $H_{1}$ : perceived usefulness berpengaruh pada prilaku mahasiswa dalam menyikapi penggunaan ELSE-U

Dimensi perceived usefulness berpengaruh pada prilaku mahasiswa dalam menyikapi penggunaan ELSE-U memiliki nilai koefisien jalur sebesar 0. dan dip1995eroleh $p$-value 
sebesar 0.075 yang lebih besar dari 0.05 sehingga keputusan yang diambil adalah menolak $\mathrm{H}_{0}$. Hal ini berarti sarana perceived usefulness berpengaruh quasi signifikan pada prilaku mahasiswa dalam menyikapi penggunaan ELSE-U.

8. Perceived ease of use berpengaruh pada prilaku mahasiswa dalam menyikapi penggunaan ELSE-U. Adapun hipotesis yang diuji dalam hal ini sebagai berikut:

$H_{0}$ : perceived ease of use tidak berpengaruh pada prilaku mahasiswa dalam menyikapi penggunaan ELSE-U

$H_{1}$ : perceived ease of use berpengaruh pada prilaku mahasiswa dalam menyikapi penggunaan ELSE-U

Hubungan antara variabel perceived ease of use berpengaruh pada prilaku mahasiswa dalam menyikapi penggunaan ELSE-U memiliki nilai koefisien jalur sebesar 0.652. dan diperoleh $p$-value sebesar 0.000 yang lebih kecil dari 0.05 sehingga keputusan yang diambil adalah menolak $\mathrm{H}_{0}$. Hal ini berarti sarana perceived ease of use berpengaruh pada prilaku mahasiswa dalam menyikapi penggunaan ELSE-U.

9. Faktor internal mahasiswa berpengaruh terhadap perceived usefulness pada penggunaan ELSE-U. Adapun hipotesis yang diuji dalam hal ini sebagai berikut:

$H_{0}$ : perceived usefulness tidak

berpengaruh pada niat mahasiswa untuk menggunakan ELSE-U

$H_{1}$ : perceived usefulness berpengaruh pada niat mahasiswa untuk menggunakan ELSE-U

Hubungan antara variabel perceived usefulness berpengaruh pada niat mahasiswa untuk menggunakan ELSE-U memiliki nilai koefisien jalur sebesar 0.194. dan diperoleh $p$-value sebesar 0.097 yang lebih besar dari 0.05 sehingga keputusan yang diambil adalah menolak $\mathrm{H}_{0}$. Hal ini berarti sarana perceived usefulness berpengaruh quasi signifikan pada niat mahasiswa untuk menggunakan ELSE-U
10. Perilaku mahasiswa dalam menyikapi penggunaan ELSE-U berpengaruh pada niat mahasiswa untuk menggunakannya; Adapun hipotesis yang diuji dalam hal ini sebagai berikut:

$H_{0}$ : prilaku mahasiswa dalam menyikapi penggunaan ELSE-U tidak berpengaruh pada niat mahasiswa untuk menggunakannya; dan

$H_{1}$ : prilaku mahasiswa dalam menyikapi penggunaan ELSE-U berpengaruh pada niat mahasiswa untuk menggunakannya.

Hubungan antara variabel prilaku mahasiswa dalam menyikapi penggunaan ELSE-U berpengaruh pada niat mahasiswa untuk menggunakannya; dan memiliki nilai koefisien jalur sebesar 0.375 . dan diperoleh $p$-value sebesar 0.003 yang lebih kecil dari 0.05 sehingga keputusan yang diambil adalah menolak $\mathrm{H}_{0}$. Hal ini berarti sarana prilaku mahasiswa dalam menyikapi penggunaan ELSE-U berpengaruh signifikan pada niat mahasiswa untuk menggunakannya.

11. Perceived ease of use berpengaruh pada niat mahasiswa untuk menggunakan ELSE-U. Adapun hipotesis yang diuji dalam hal ini sebagai berikut:

$$
\begin{aligned}
H_{0}: & \text { perceived ease of use tidak } \\
& \text { berpengaruh pada niat mahasiswa } \\
& \text { untuk menggunakan ELSE-U } \\
H_{1}: & \text { perceived ease of use berpengaruh } \\
& \text { pada niat mahasiswa untuk } \\
& \text { menggunakan ELSE-U }
\end{aligned}
$$

Hubungan antara variabel faktor internal mahasiswa dengan perceived usefulness pada penggunaan ELSE-U memiliki nilai koefisien jalur sebesar 0.198. dan diperoleh $p$-value sebesar 0.094 yang lebih besar dari 0.05 sehingga keputusan yang diambil adalah menolak $\mathrm{H}_{0}$. Hal ini berarti sarana perceived ease of use berpengaruh quasi signifikan pada niat mahasiswa untuk menggunakan ELSE-U. 


\section{KESIMPULAN DAN SARAN}

\section{Kesimpulan}

Berdasarkan analisis yang telah dijelaskan pada bab sebelumnya, dapat ditarik kesimpulan bahwa faktor internal dan eksternal mahasiswa tidak berpengaruh terhadap perceived ease of use pada penggunaan ELSE-U, faktor organisasi (program studi, fakultas, dan universitas) berpengaruh signifikan terhadap perceived usefulness dan perceived ease of use pada penggunaan ELSE-U, sedangkan prilaku mahasiswa dalam menyikapi penggunaan ELSE-U berpengaruh signifikan pada niat mahasiswa untuk menggunakannya

\section{Saran}

Pada penelitian ini indikator-indikator yang digunakan untuk menjelaskan variabel laten di dalam model belum dapat secara opitmal menjelaskan pengaruh variabel latennya, sehingga diharapkan untuk penelitian selanjutnya perlu mengkaji secara teoritis indikator-indikator lain yang lebih sesuai.

\section{DAFTAR PUSTAKA}

Brown, B.L., Hendrix, S.B., Hedges, D.W. \& Smith, T.B., 2012. Multivariate Analysis for the Biobehavioral and Social Sciences: A Graphical Approach. New Jersey: John Wiley \& Sons, Inc.

Butler, R.W., 1993. Tourism - an evolutionary perspective. In J.G. Nelson, R.W. Butler \& G. Walls, eds. Tourism and Sustainable Development: Monitoring, Planning, Managing. Waterloo: Geography Publication Series \# 52.

Churchill, Jr., G.A., 1979. A Paradigm for Developing Better Measures of Marketing Constructs. Journal of Marketing Research, 16(1), pp.64-73

Darmawan, Deni. 2012. Inovasi Pendidikan (Pendekatan Praktek Teknologi Multimedia dan Pembelajaran Online). PT. Remaja Rosdakarya. Bandung

David, A. K. (1998). Multiple factor models. Retrieved May 14, 2007 from http://davidakenny.net/cm/mfactor.htm
Davis, F. D. (1986). A technology acceptance model for empirically testing new end-user information systems: Theory and results. Doctoral dissertation. Cambridge, MA: MIT Sloan School of Management.

Davis, F. D. (1989). Perceived usefulness, perceived ease of use, and user acceptance of information technology. MIS Quarterly, 13(3), 319-339.

Davis, F. D., Bagozzi, R. P., \& Warshaw, P. R. (1989). User acceptance of computer technology: A comparison of two theoretical models. Management Science, 35(8), 982-1003.

Duncan, Jack W., 1981. Organizational Behavior. Boston: Houghton Mifflin Coy.

Gilbert, J. (2001). Leveraging Effective ICT Strategies for Sustainable Development. Workshop on Sectoral Planning for Information Technology. Pembentangan di Regional Initiative for Information and Communication Technology Strategies Conference 2001, Pusat Dagangan Dunia Putra, Kuala Lumpur, Malaysia, 24-26 July 2001.

Gudono, 2016. In: Analisis Data Multivariat. Yogyakarta: BPFE, p. 256.

Hair, J.F., Anderson, R.E., Tatham, R.L. \& Black, W.C., 1995. Multivariate Data Analysis with Readings. 4th ed. New Jersey: Prentice-Hall, Inc.

Igbaria, M. (1993) User acceptance of microcomputer technology: An empirical test. OMEGA International Journal of Management Science, 21, 73-90.

Igbaria, M., Schiffman, S. J., \& Weickowski, T. J. (1994). The respective roles of perceived usefulness and perceived fun in the acceptance of microcomputer technology. Behaviour and Information Technology, 13, 349-61.

Jogiyanto. (2007). Model Kesuksesan Sistem Teknologi Informasi. Yogyakarta : Andi Offset.

Jogiyanto. (2007). Sistem Informasi Keperilakuan. Yogyakarta : Andi Offset.

Jogiyanto, HM, 2008, “Metodologi Penelitian Sistem Informasi: Pedoman dan Contoh Melakukan Penelitian di Bidang Sistem 
Teknologi Informasi”, Yogyakarta:Andi.: Penerbit Andi.

Lihawa, Sri Mariyati. 2012. Penerapan Technology Acceptance Model (TAM) untuk Menganalisa Sikap Pengguna Terhadap Teknologi Sistem Informasi Akademik. http://ti.fatek.ung.ac.id/down.php?file=SriM ariyatiLihawa.pdf. (15 Juni 2013).

Nunnaly, J.C., 1975. Psychometric Theory. 25 Years Ago and Now. Educational Researcher, 4(10), pp.7-14;19-21. 